\title{
The efficacy of IL-6 inhibitor Tocilizumab in reducing severe COVID-19 mortality: A systematic review
}

\author{
Avi Gurion Kaye ${ }^{\text {Corresp., } 1}$, Robert Siegel ${ }^{1,2}$ \\ ${ }^{1}$ Human Biology, Stanford University, Stanford, California, United States \\ 2 Microbiology \& Immunology, Stanford University, Stanford, California, United States \\ Corresponding Author: Avi Gurion Kaye \\ Email address: agkaye@stanford.edu
}

Background: In the absence of highly effective antiviral therapies against SARS-CoV-2, it is crucial to counter the known pathophysiological causes of severe COVID-19. Evaluating the efficacy existing drugs may expedite the development of such therapeutics. Severe COVID-19 is largely the result of a dysregulated immune response characterized by lymphocytopenia, neutrophilia and critical hypercytokinemia, or "cytokine storm," which is largely mediated by the cytokine interleukin-6 (IL-6). The IL-6 inhibitor tocilizumab (TCZ) could potentially suppress the effects of the pro-inflammatory cytokine and thereby lower mortality from the disease. This systematic analysis aimed to investigate and synthesize existing evidence for the efficacy of TCZ in reducing COVID-19 mortality. Methodology: PubMed and SearchWorks searches were performed to locate clinical studies with primary data on TCZ treatment for severe COVID-19. Sixteen case-control studies comparing mortality between TCZ and standard of care (SOC) were identified for quantitative synthesis. The systematic analysis was pre-approved through PROSPERO (CRD42020193479). Results: Combined mortality for the TCZ-treated and SOC groups were $26.0 \%$ and $43.4 \%$ respectively. In all but one of the studies, the odds ratio of mortality from COVID-19 pointed towards lower fatality with TCZ versus the SOC. A combined random effects odds ratio calculation yielded an odds ratio of $0.453(95 \% \mathrm{Cl}$ 0.376-0.547, $\mathrm{p}<0.001)$. Additionally, eighteen uncontrolled trials were identified for qualitative analysis producing a raw combined mortality rate of $16.0 \%$. Conclusions: Important caveats to this research include the lack of prospective randomized control trials (RCTs) and the absence of data from the large COVATA study from the published literature. However, results from this systematic analysis of published research provide positive evidence for the potential efficacy of TCZ to treat severe COVID-19, validating the ethical basis and merit of ongoing randomized controlled clinical trials. 


\section{The Efficacy of IL-6 Inhibitor Tocilizumab in Reducing Severe COVID-19 Mortality: A Systematic Review}

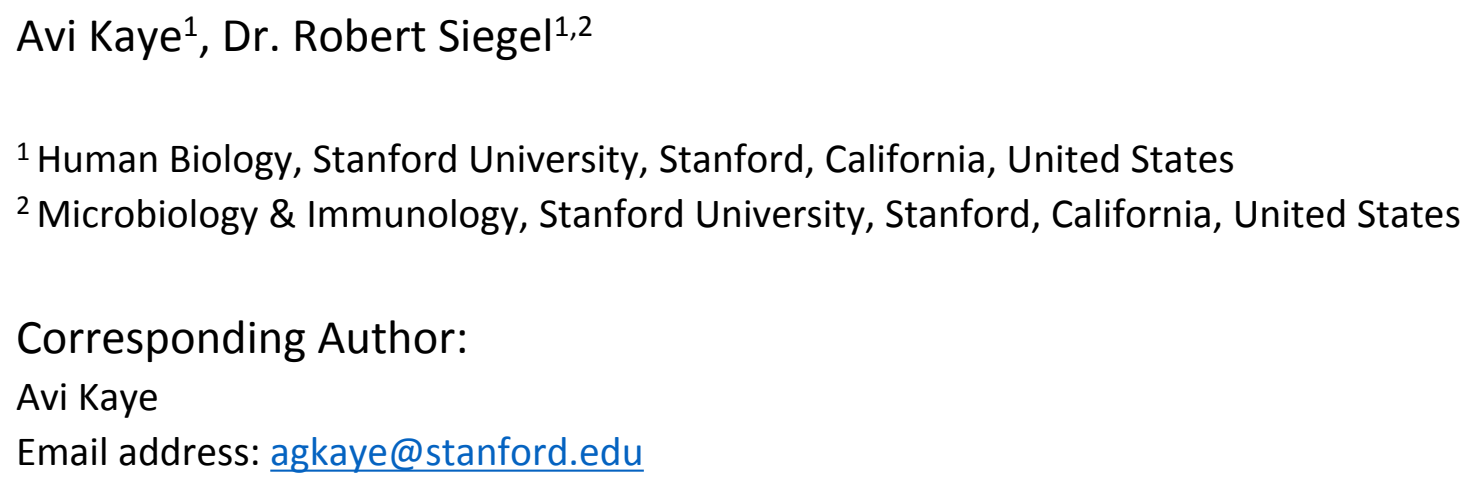

\section{Abstract}

Background: In the absence of highly effective antiviral therapies against SARS-CoV-2, it is crucial to counter the known pathophysiological causes of severe COVID-19. Evaluating the efficacy existing drugs may expedite the development of such therapeutics. Severe COVID-19 is largely the result of a dysregulated immune response characterized by lymphocytopenia, neutrophilia and critical hypercytokinemia, or "cytokine storm," which is largely mediated by the cytokine interleukin-6 (IL-6). The IL-6 inhibitor tocilizumab (TCZ) could potentially suppress the effects of the pro-inflammatory cytokine and thereby lower mortality from the disease. This systematic analysis aimed to investigate and synthesize existing evidence for the efficacy of TCZ in reducing COVID-19 mortality. Methodology: PubMed and SearchWorks searches were performed to locate clinical studies with primary data on TCZ treatment for severe COVID-19. Sixteen case-control studies comparing mortality between TCZ and standard of care (SOC) were identified for quantitative synthesis. The systematic analysis was pre-approved through PROSPERO (CRD42020193479). Results: Combined mortality for the TCZ-treated and SOC groups were $26.0 \%$ and $43.4 \%$ respectively. In all but one of the studies, the odds ratio of mortality from COVID-19 pointed towards lower fatality with TCZ versus the SOC. A combined random effects odds ratio calculation yielded an odds ratio of 0.453 (95\% Cl 0.376-0.547, $\mathrm{p}<0.001$ ). Additionally, eighteen uncontrolled trials were identified for qualitative analysis producing a raw combined mortality rate of $16.0 \%$. Conclusions: Important caveats to this research include the lack of prospective randomized control trials (RCTs) and the absence of data from the large COVATA study from the published literature. However, results from this systematic analysis of published research provide positive evidence for the potential efficacy of TCZ to treat severe COVID-19, validating the ethical basis and merit of ongoing randomized controlled clinical trials. 


\section{Introduction}

Coronavirus Disease 2019 (COVID-19) - caused by the novel Severe Acute Respiratory Syndrome Coronavirus 2 (SARS-CoV-2) - manifests in a broad range of disease severity. Roughly $85 \%$ of confirmed cases present as a mild respiratory illness defined as minor fatigue, low-grade fever and dry cough, 15\% develop severe pneumonia requiring hospitalization and $5 \%$ become critical indicated by acute respiratory distress syndrome (ARDS), septic shock, and multi-organ failure resulting in ICU admission, mechanical ventilation, and death. ${ }^{1}$ The most significant known risk factors for COVID-19-related death are increasing age, chronic comorbidities including diabetes, cardiac disease, pulmonary and kidney dysfunction and male sex. ${ }^{2} \mathrm{~A}$ dysregulated immune response - characterized by decreased T-cell counts, increased inflammatory cytokines and extra-pulmonary systemic hyperinflammation syndrome - is principally responsible for inducing critical pulmonary failure observed in COVID-19 and largely driven by interleukin-6 (IL-6). ${ }^{3}$ This systematic review (Fig. 1) concerns the efficacy of an interleukin-6 inhibitor, tocilizumab (TCZ) in reducing severe COVID-19 mortality.

\section{COVID-19 Dysregulated Immune Response and the Role of IL-6}

Severe COVID-19 is characterized by a dysregulated immune response to SARS-CoV-2 infection that is implicated in disease mortality even after viral load decreases. ${ }^{4}$ The immune dysregulation presents with two sequential and diametrically opposed reactions that both instigate symptom aggravation. ${ }^{5}$ The first pattern is impaired adaptive immune response with lymphocytopenia, which includes markedly reduced CD4+ and CD8+ T-cells, B-cells and natural killer (NK) cells. While T-cells are significantly decreased in all COVID-19 patients, reduction in B and NK cells are more affected in severe cases. ${ }^{6,7}$ Adaptive immune cell depletion impairs the body's ability to clear the virus and mitigate inflammatory reactions. ${ }^{8}$

The second deleterious response is an over-activation of the innate immune system. This pathogenic response is characterized by an increase in neutrophils and pro-inflammatory cytokines including IL-6, IL-1 $\beta$, IL-2, IL-8, CCL3 and TNF- $\alpha$. The rapidly increasing cytokine levels - also known as a "cytokine storm" - drives progression to septic shock, tissue damage and multiple organ failure (heart, liver, kidney, respiratory). ${ }^{5}$ The effects are instigated by excessive NF-KB and JAK/STAT pathway activation, alarmin release by damaged epithelial cells, neutrophil and macrophage infiltration, and alveolar damage by vessel permeability and alveolar wall thickening. 8

Roughly three-quarters of patients in severe condition present with IL- 6 mediated respiratory failure while the other quarter occurs predominately through IL-1 $\beta$ macrophage activation. ${ }^{9}$ IL- 6 concentration is thus a reliable predictor of COVID-19 severity as it is significantly elevated in fatal cases. ${ }^{10}$ IL- 6 has pleotropic effects including hematopoiesis, metabolic regulation, inflammation, autoimmunity and acute phase response. ${ }^{11}$ Some IL-6dependent outcomes help stave off infections such as directing neutrophil migration to the infection site, increasing CD8+ T cell cytolytic capacity, and regulating antiviral thermostatic reactions. However, IL-6 is also implicated in viral infection disease progression as it leads to tissue permeability and edema, reduces IFN- $\gamma$ production, drives anti-apoptotic molecules and 
promotes excessive neutrophil survival. The above adverse effects promote lethal inflammation and enable viral infiltration to distant organs. ${ }^{12}$ Furthermore, elevated serum IL- 6 is associated with impaired cytotoxic activity of NK cells, thus weakening their virus-killing capacity. ${ }^{13}$ IL- 6 is known to increase the rate of fibrotic clot formation, so it also may play a role in the thrombotic complications observed in COVID-19.12 The renin-angiotensin system, which controls blood pressure and electrolyte balance, is an additional important factor in IL-6 modulation and COVID-19 pathology. As virus binds ACE2, thus reducing its availability, there is an increase of angiotensin II in COVID-19 patients, creating a positive feedback loop that advances proinflammatory signaling. ${ }^{12}$ The responses and physiological effects of IL-6 release are summarized in Figure 2.

\section{COVID-19 Treatments}

\section{Antivirals}

Without a targeted drug for COVID-19, scientists and clinicians are attempting to rapidly find alternative treatments and solutions to combat the disease's lethal immunological effects. ${ }^{14}$ One strategy is to utilize existing antiviral drugs with the expectation that they may exhibit similar effects against SARS-CoV-2. One of the more promising treatments is RNAdependent RNA polymerase inhibitor remdesivir which is shown to reduce COVID-19 mortality but is less effective in severe cases. ${ }^{15}$ Other commonly used antivirals are hydroxychloroquine and chloroquine. Despite widespread utilization for COVID-19 patients, evidence is lacking for the clinical efficacy and prophylactic properties of hydroxychloroquine or chloroquine despite their in vitro antiviral and in vivo immunomodulatory properties. ${ }^{16}$

\section{Immune Suppressants}

There are numerous investigations of existing immune suppressing and anti-cytokine interventions to counter the dysregulated, excessive immune response. After early evidence and recommendations against the use of corticosteroids to treat severe COVID-19, 17,18 a large randomized evaluation of dexamethasone found that the drug significantly reduced 28-day mortality in patients included in the study (rate ratio $0.83 ; 95 \% \mathrm{Cl} 0.74-0.92 ; \mathrm{p}<0.001$ ). However, mortality rate reductions varied depending on baseline respiratory demands upon randomization as there was reduction for patients on mechanical ventilation and oxygen but not for patients without respiratory support. ${ }^{19}$ As of mid-August 2020, the WHO modified their recommendation against corticosteroids to include judicious administration under respiratory failure with ARDS. ${ }^{20}$ Because of the systemic effects of corticosteroids, more options for targeted immune regulation is warranted. Common targets for inhibition include IL-6, the IL-1 family (IL-1 $\beta$ and IL-18), TNF- $\alpha$ and IFN- $\gamma$ cytokines and the JAK/STAT pathway. ${ }^{8}$

IL-6 is a particularly promising target due to its correlation with ARDS severity and mortality. ${ }^{21}$ IL-6 inhibitors are already successfully utilized for other cytokine storm syndromes such as adverse T cell therapy reactions and Still's disease-associated hemophagocytic lymphohistiocytosis. ${ }^{8}$ In COVID-19, IL-6 inhibitors should be carefully administered with appropriate timing due to its control of viral replication. ${ }^{22}$

\section{IL-6 Inhibitor Tocilizumab}


Tocilizumab (TCZ) [Actemra] is a recombinant monoclonal antibody with a humanized murine variable domain and a human IgG1 constant domain. TCZ binds to both membranebound and soluble IL-6 receptors, thus preventing IL-6 mediated signal transduction (Fig. 3). The drug was initially developed to treat rheumatoid arthritis and now it is also approved for giant cell arteritis and similar autoimmune ailments. Its safety profile was analyzed in a phase III double-blind placebo-controlled trial and it is reportedly effective in treating other cases severe cytokine release syndrome such as chimeric antigen receptor T-cell immunotherapy. ${ }^{11}$

While TCZ is not yet approved for treatment of COVID-19, clinicians across the globe are utilizing the drug under emergency use authorization, including in the United States. One of the largest initial observational studies of TCZ evaluated 547 COVID-19 ICU patients in New Jersey comparing the survival rate of 134 individuals treated with standard of care (SOC) and TCZ with SOC controls finding a $46 \%$ and $56 \%$ mortality rate respectively and a 0.76 adjusted hazard ratio. ${ }^{23}$ However, there was insufficient statistical power to conclude clinical efficacy of TCZ with the clinical data and they only focused cases that already progressed to a critical stage leading to an inflated mortality rate for both groups.

Randomized controlled trials (RCT) are the gold standard for evaluating the clinical efficacy of a drug. The first analyzed RCT for TCZ presented negative results. Genentech (Roche) - the producer of TCZ - discontinued their 450-participant phase III trial COVACTA because it failed to meet the primary endpoint of improved clinical status after 4 weeks with TCZ versus the SOC. ${ }^{24}$ The disappointing outcome from COVACTA places serious doubt on the efficacy of TCZ against COVID-19. Additionally, another IL-6 inhibitor carlumab failed its Phase III RCT in the United States but still has some ongoing (NCT04322773, NCT04327388, NCT04412772). ${ }^{25}$ Other IL-6 inhibitors under investigation include siltuximab (SYLVANT, NCT04322188) and fingolimod (NCT04280588) Nonetheless, several phase III and phase II RCTs remain in progress into at least September (REMDACTA, NCT04409262; NCT04372186, NCT04356937) and healthcare providers are still currently administering TCZ globally for advanced COVID-19 cases. However, the logic of suppressing IL-6 remains convincing. Therefore, it is essential that the known impact of TCZ is analyzed in a systematic manner to ascertain whether its continuing use is ethical, even in RCTs. Since dexamethasone is a broadly acting immunosuppressant, it should be noted that the use of this drug in clinical trials may obscure the effects of more targeted immunomodulatory drugs like TCZ.

The most recent systematic reviews on the use of TCZ for COVID-19 identified clinical trials without data synthesis ${ }^{26}$ and performed a large meta-analysis of controlled trials but did not address issues with the individual studies. ${ }^{27}$ Therefore, this systematic review will synthesize the evidence from individual case-control studies, analyze uncontrolled trials and evaluate their methods to determine whether the drug is potentially effective at reducing severe COVID-19-related mortality, thus corroborating the logic for continuing RCTs to evaluate the potential use of IL- 6 inhibitors.

\section{Systematic Review Methods and Statistics}


Articles utilized for the systematic review were selected from a PubMed search on August 4, 2020. Both authors screened and reviewed each paper, and disagreements were resolved by a third reader. Data was independently extracted by the readers. For the initial screening, the primary search terms were "COVID-19" or "SARS-CoV-2" and "tocilizumab." Papers with primary data for a case-control study comparing mortality rate from severe COVID19 between TCZ and standard of care (SOC) were included for data synthesis. Uncontrolled studies on severe COVID-19 mortality with TCZ were reviewed separately without data synthesis. Exclusion criteria included papers without primary data, case reports, reviews, protocols, and studies without mortality numbers available or patient data that may be used in another studies. An additional search was performed on SearchWorks to identify case-control studies not found in PubMed.

For each study included in the synthesis, the mortality rate for the TCZ and SOC group were calculated. In the controlled studies, the odds ratio (RR) of mortality from COVID-19 with TCZ versus the SOC was determined followed by the $95 \%$ confidence interval $(\mathrm{Cl})$ and $\mathrm{p}$-value calculation. The data from the individual controlled studies were synthesized by a random effects meta-analysis calculation using MedCalc software. MedCalc was also used to perform a sample size calculation with an alpha of 0.01 and power of $90 \%$ to detect a difference between the total crude TCZ and SOC mortality rates.

The systematic review protocol was pre-registered with PRISMA and approved on June 22, 2020 (CRD42020193479).

\section{Results}

A total of 314 articles were identified by the initial PubMed search and three additional case-control studies were found on a SearchWorks (Fig. 1). ${ }^{28} 38$ articles were selected for fulltext review yielding 16 uncontrolled studies for qualitative analysis and 18 case-control studies for both quantitative synthesis and qualitative analysis. The study characteristics for the controlled studies are summarized in Supplementary Table 1 while the uncontrolled studies are outlined in Supplementary Table 3.

\section{Controlled Studies}

The systematic review of sixteen controlled studies encompassed a total of 1008 TCZtreated and 1537 SOC control patients (Table 1). 13 of the studies occurred in a single medical center while the remaining three aggregated data from multiple hospitals. The largest patient contributions to the analysis were from the multiple-hospital studies [Ip et al. and Guaraldi et al.] The baseline patient characteristic for all but one study [Guaraldi et al.] was severe COVID19 , generally qualified by oxygen supplementation needs. Ip et al., Eimer et al. and Potere et al. only analyzed patients who were already admitted into the ICU. $61 \%$ and $44.8 \%$ of both cases and controls in Rojas-Marte et al. and Roumier et al. respectively began the trial in critical condition. There was some variation in TCZ administration and SOC treatments, the most common being hydroxychloroquine - utilized in all but one study (Capra et al.) - and 
199

200

201

202

203

204

205

206

207

208

209

210

211

212

213

214

215

216

217

218

219

220

221

222

223

224

225

226

227

228

229

230

231

232

233

234

235

236

237

238

239

lopinavir/ritonavir. Length of observation ranged from 7 days to 30 days with endpoints of death or discharge. Mean age of participants in the treatment and control groups was 55.5 to 76.8 with no more than 6.1 years separating the two groups within one study.

Combined mortality for the TCZ-treated and SOC groups were $26.0 \%$ and $43.4 \%$ respectively. All of the studies trended toward lower mortality from severe COVID-19 with TCZ versus the SOC with the exception of Patel et al. which showed no benefit. Six studies yielded a statistically significant result (Capra et al., Guaraldi et al., Gokhale et al., Rossotti et al., Somers et al., Potere et al.) (Fig. 4). A random effects odds ratio analysis generated an odds ratio of $0.453(95 \% \mathrm{Cl} 0.376-0.547)$ with a $p$-value less than 0.001 . A sample size analysis with alpha of 0.01 and power of $90 \%$ determined that 392 total case and control patients are needed to detect a difference between $26.0 \%$ and $43.4 \%$ mortality. With the exception of Capra et al., the studies also scattered symmetrically around the overall odds ratio from the analysis suggesting a low likelihood of publication bias (Fig. 5). TCZ patients in five studies had significant secondary bacteremia but one reported a lower rate than the SOC (Rojas Marte et al.). Eight studies reported no adverse effects from TCZ.

No pattern was identified in terms of the length of hospitalization between TCZ and SOC. Nine studies found a lower rate of ICU admission with TCZ, four with statistical significance (Colaneri et al., Roumier et al., Guaraldi et al., Canziani et al.) (Supplementary Table 1). Only one study (Colaneri et al.) provided both baseline and post-treatment values for biomarkers such as IL-6, CRP, lymphocytes, neutrophils, ALT etc.

Several variables varied between studies that could impact the mortality rate results. These include SOC, observation time, TCZ administration, treatment date, baseline clinical characteristics, geographic location and resources and mean/median age. Study design was also an important varying factor that may change results as nine of the sixteen studies matched cases with controls and thirteen studies were retrospective as opposed to prospective cohort.

\section{Uncontrolled Studies}

The 18 uncontrolled trials encompassed 886 total patients who received TCZ. The mortality rate from severe COVID-19 ranged from $0 \%$ to $42.4 \%$ (SD 9.87\%), although the two studies with $0 \%$ had relatively small sample sizes ( 20 for Xu et al. and 12 for Borku Uysal et al.). The raw overall mortality rate from the 12 studies is $16.0 \%$. The initial patient severity level ranged from "severe" - requiring supplemental oxygen - to ICU admission. One study only investigated ICU patients (Issa et al.) and others included as many as $77.7 \%$ on MV. SOC varied more widely in the uncontrolled trials than the controlled, but hydroxychloroquine was still the most common additional drug used. Few major side effects such as bacterial/fungal infections and increased hepatic enzymes were reported.

Comparing the combined data between uncontrolled $(n=18)$ and controlled trials $(n=14)$ with TCZ (Table 2), excluding controlled studies with all the patients initially in the ICU, the mortality rate was $19.3 \%$ and $16.0 \%$ respectively $(p=0.384)$. 


\section{Discussion}

241

242

243

244

245

246

247

248

249

250

251

252

253

254

255

256

257

258

259

260

261

262

263

264

265

266

267

268

269

270

271

272

273

274

275

276

277

278

279

\section{Controlled Studies}

The purpose of this systematic analysis was to analyze and synthesize clinical data on the efficacy of TCZ treatment against severe COVID-19. In the sixteen existing case-control trials published as of August 4, 2020, combined mortality for the TCZ-treated and SOC groups were $26.0 \%$ and $43.4 \%$ respectively. All of the studies at least trended towards reduced mortality with TCZ - with one exception (Patel et al.) that showed no benefit - (Fig. 4) including six with statistical significance (Capra et al., Guaraldi et al., Gokhale et al., Rossotti et al., Somers et al., Potere et al.). After performing a quantitative synthesis, the random effects odds ratio of mortality with TCZ versus the SOC was $0.453(95 \% \mathrm{Cl} 0.376-0.547, \mathrm{p}<0.001)$ illustrating a reported difference in patient outcomes associated with the use of TCZ. There was no indication of publication bias except for Capra et al. (Fig. 5) and the number of patients in the meta-analysis exceeded the 392 required total case and control patients to statistically detect the difference in mortality rate. Some studies also secondarily investigated the rate of ICU admission with nine finding a lower rate with TCZ versus SOC and four having statistical significance (Colaneri et al., Roumier et al., Guaraldi et al., Canziani et al.) (Supplementary Table 1). Although the value of any single controlled clinical study does not hold definitive proof of efficacy, the consistent positive trend and statistical significance from the combined data in this analysis corroborates TCZ's potential positive effects.

TCZ also appears to be mostly benign as few serious side effects were reported in most of the studies. As expected from an immune suppressant, the most notable adverse event was secondary infection reaching as high as $32.4 \%$ of participants (Rossotti et al.) but not at a statistically greater rate than SOC.

It is important to acknowledge that only one of the studies (Guaraldi et al.) randomized who received TCZ which introduces the possibility for selection bias into each study's research methodology. Additionally, only one study provided both baseline and post-treatment values for important biomarkers, notably IL-6, CRP, neutrophils and lymphocytes. Specific strengths and shortcomings for the controlled trials are outlined in Supplementary Table 2, which points towards additional methodological issues in each of the studies analyzed. Common themes include short observation timing, small sample size, difference in treatment time (later patients may benefit from better SOC), variation in disease severity within groups which can confound results, and changes to TCZ administration mid-study. Future clinical trials can be improved by addressing the methodological issues outlined above.

Additionally, it is possible that individual studies finding a negative effect of TCZ were not published and could not be accounted for in this systematic review. Most notably, the known public results from the COVACTA trial were not yet released in published format as of late August and were therefore not included in the quantitative synthesis. It is significant that the RCT COVACTA did not find reduced COVID-19 mortality with TCZ versus SOC, placing doubt as to the drug's potential efficacy and the ethical basis of continuing other trials. Nonetheless, there are still multiple RCTs in progress to evaluate the efficacy of TCZ (NCT04409262; 
280 NCT04372186, NCT04356937, NCT04412772). Data from this systematic review adds merit to

281

282

283

284

285

286

287

288

289

290

291

292

293

294

295

296

297

298

299

300

301

302

303

304

305

306

307

308

309

310

311

312

313

314

315

316

317

318

319

320

clinical investigations despite the initial negative results from COVACTA.

\section{Uncontrolled Studies}

Uncontrolled trials were analyzed separately to explore trends in treatment data. Recognizing the wide variation in patient outcomes between the studies, the combined mortality rate from 12 single-arm studies using TCZ against severe COVID-19 was 16.0\% (SD 9.87\%). However, without clinical trials, it is difficult to determine the baseline rate COVID-19 mortality for hospitalized patients to compare with the rate calculated from the uncontrolled trials. Clinical data reviews are subject to geographic and demographic differences, such as a 5700-person evaluation in New York from April 2020 that found a 21\% fatality rate for hospitalized patients which is higher than other locations and later studies. ${ }^{44}$ Participants must be matched to controls to eliminate bias and account for other confounding factors to draw definitive conclusions. Comparing the uncontrolled and controlled trials from this systematic review, excluding controlled trials with all the patients initially in the ICU (Ip et al. and RojasMarte et al.), there was no significant difference in mortality rate between the two experimental approaches $(p=0.384)$. This observation supports the assertion that the combined reported results from the uncontrolled results from this systematic analysis are potentially accurate and corroborate the merit in evaluating TCZ efficacy. Nevertheless, the uncontrolled trials should still be evaluated with some degree of skepticism. Specific shortcomings for the individual uncontrolled trials are delineated in Supplementary Table 4.

\section{TCZ Treatment Timing}

There is a question of timing for the IL- 6 blocking treatment. All of the studies evaluated included only patients who were already in a severe disease state. Given the patterns of COVID19 pathology and immune dysregulation, it may be logical to defer TCZ until the inflammatory phase due to the positive effects of IL- 6 release in the acute infection stage which theoretically prevents SARS-CoV-2 proliferation. Given the unique, aberrant immune reaction in COVID-19, some researchers argue that the optimal time to employ targeted immune suppressants such as TCZ, in order to curtail and not enhance mortality, is when patients begin to trend towards hypoxia and inflammation. ${ }^{3}$ However, this timing is theoretical and must be demonstrated in a RCT.

\section{Limitations}

There are notable limitations to this systematic analysis and qualitative synthesis of TCZ. First, only one of the studies presented randomized who received TCZ, opening the possibility for selection bias and confounding factors that cannot be accounted for statistically. This systematic analysis synthesizes data from studies with different SOCs, geographies, resources, demographics, and TCZ dosing amount, number and timing. It is not possible to conclude that TCZ is efficacious in reducing COVID-19 mortality, simply that the data trends towards a lower odds ratio for mortality with incomplete generalizability. Similarly, while patients across all of the studies were at least in severe condition, the combined data still represents individuals at various stages of COVID-19. Not all of the studies offered a longitudinal time component, so an

Peer] reviewing PDF | (2020:09:52525:1:1:NEW 1 Oct 2020) 
321

322

323

324

325

326

327

328

329

330

331

332

333

334

335

336

337

338

339

340

341

342

343

344

345

346

347

348

349

350

351

352

353

354

355

356

357

358

359

360

overall hazard ratio or Kaplan-Meir survival curve cannot be produced. Additionally, many patients were still in the hospital at the end of the observation period potentially skewing the mortality rate. Importantly, in the random effects odds ratio calculation, there was no control for age, sex and baseline characteristics like individual studies were able to accomplish. As noted, the uncontrolled trials on TCZ cannot be adequately evaluated without direct comparison to a control group. Finally, it is possible that studies finding a negative effect of TCZ were not published and not accounted for in this systematic review.

\section{Conclusions}

A systematic review of the clinical data of IL-6 inhibitor tocilizumab (TCZ) for severe COVID-19 points towards efficacy in reducing mortality from the disease. There are numerous notable methodological limitations in the studies analyzed including the lack of randomization in controlled trials and potential for an inadequate evaluation due to unpublished data. However, the results from this systematic analysis corroborate the logic and ethical basis for ongoing phase III RCTs on TCZ. In light of this analysis, several factors would facilitate the evaluation of TCZ as a therapeutic for the immune dysregulation associated with COVID-19: 1) Publication of the results from unpublished clinical trials, 2) Completion of additional randomized controlled trials especially where the potentially complicating effects of dexamethasone may be ruled out, 3) Comparison of TDZ findings with results assessing other IL6 inhibitors such as sarilumab or siltuximab, and 4) Completion of additional metabolic studies measuring the levels of immune mediators and biomarkers in SARS-CoV-2 infected animal models and humans treated with TCZ. It will also be useful to assess the possibility of therapeutic synergy between antiviral agents such as remdesivir and TCZ. The use of TCZ outside the clinical trial context is discouraged until results from these clinical trials are released.

\section{References}

1. Huang, C., Wang, Y., Li, X., Ren, L., Zhao, J., Hu, Y.,L., Zhang, Fan, G. Xu, J., Gu, X., Cheng, Z., Yu, T., Xia, J., Wei, Y., Wu, W., Xie, X., Yin, W., Li, H., Liu, M., Xiao, Y., Gao, H., Guo, L., Xie, J., Wang, G., Jiang, R., Gao, Z., Jin, Q., Wang, J., Cao, B. Clinical features of patients infected with 2019 novel coronavirus in Wuhan, China. The Lancet. 2020; 395: 497-506

2. Docherty, A., Harrison, E., Green, C., Hardwick, H., Pius, R., Norman, L., Holden, K., Read, J., Dondelinger, F., Carson, G., Merson, L., Lee, J., Sigfrid, L., Halpin, S., Jackson, C., Gamble, C., Horby, P., Nguyen-Van-Tam, J., Russell, C., Dunning, J., Openshaw, P., Baillie, K., Semple, M. Features of 20,133 UK 
361

362

363

364

365

366

367

368

369

370

371

372

373

374

375

376

377

378

379

380

381

382

383

384

385

386

387

388

389

390

391

392

393

394

395

396

397

398

patients in hospital with covid-19 using the ISARIC WHO Clinical Characterization Protocol: prospective observational cohort study. BMJ. (May 22, 2020). doi: 10.1136/bmj.m1985

3. Siddiqi, H. \& Mehra, M. COVID-19 Illness in Native and Immunosuppressed States: A ClinicalTherapeutic Staging Proposal. Journal of Heart and Lung Transplantation. (March 25, 2020). doi: 10.1016/j.healun.2020.03.012

4. Blanco-Melo, D., Nilsson-Payant, B., Liu, W., Uhl, S., Hoagland, D., Moller, R., Jordan, T., Oishi, K., Panis, M., Sachs, D., Wang, T., Schwatz, R., Lim, J., Albrecht, R., tenOever, B. Imbalance Host Response to SARS-CoV-2 Drives Development of COVID-19. Cell. (May 28, 2020). doi: 10.1016/j.cell.2020.04.026

5. Cao, X. COVID-19: immunopathology and its implications for therapy. Nature. (May 2020). doi: 10.1038/s41577-020-0308-3"

6. Shi, Y. Immunopathological characteristics of coronavirus disease 2019 cases in Guangzhou, China. medRxiv. (March 16, 2020). doi: 10.1101/2020.03.12.20034736

7. Zheng, M., Gao, Y., Wang, G., Song, G., Liu, S., Sun, D., Xu, Y., Tian, Z. Functional exhaustion of antiviral lymphocytes in COVID-19 patients. Cellular \& Molecular Immunology. March 7, 2020; 17:533-535. doi: $10.1038 / \mathrm{s} 41423-020-0402-2$

8. Jamilloux, Y., Henry, T., Belot, A., Viel, S., Fauter, M., Jammal, T., Walzer, T., Francois, B., Seve, P. Should we stimulate or suppress immune responses in COVID-19? Cytokine and anti-cytokine interventions. Autoimmunity Reviews. (April 26, 2020). doi: 10.1016/j.autrev.2020.102567

9. Giamarellos-Bourboulis, E., Netea, M., Rovina, N., Akinosoglou, K., Antoniadou, A., Antonakos, N., Damoraki, G., Gkavogianni, T., Adami, M., Katsaounou, P., Ntaganou, M., Kyriakopoulou, M., Diopoulos, G., Koutsodimitropoulos, I., Velissaris, D., Koufargyris, P., Karageorgos, A., Katrini, K., Lekakis, V., Lupse, M., Kotsaki, A., Renieris, G., Theodoulou, D., Panou, V., Koukaki, E., Koulouris, N., Gogos, C., Koutsoukou, A. Complex Immune Dysregulation in COVID-19 Patients with Severe Respiratory Failure. Cell Host \& Microb. June 2020; 27: 1-9. doi: 10.1016/j.chom.2020.04.009

10. Zhou, F., Yu, T., Du, R., Fan, G., Liu, Y., Liu, Z., Xiang, J., Wang, Y., Song, B., Gu, X., Guan, L., Wei, Y., Li, H., Wu, X., Xu, J., Tu, S., Zhang, Y., Den, H., Cao, B. Clinical course and risk factors for mortality of adult inpatients with COVID-19 in Wuhan, China: a retrospective cohort study. The Lancet. (March 11, 2020);395:1054-1062. doi: 10.1016/S0140-6736(20)30566-3

11. Zhang, C., Wu, Z., Li, J., Zhao, H., Wang, G. Cytokine release syndrome in severe COVID-19: interleukin-6 receptor antagonist tocilizumab may be the key to reduce mortality. Int J Antimicrob Agents. (May 2020). 55(5): 105954. doi: 10.1016/j.ijantimicag.2020.105954

12. Gubernatorova, E., Gorshkova, E., Polinova, A., Drutskaya, M.S. IL-6: relevance for immunopathology of SARS-CoV-2. Cytokine and Growth Factor Reviews. (May 17, 2020). doi: 10.1016/j.cytogfr.2020.05.009

13. Mazzoni, A., Salvati, L., Maggi, L., Capone, M., Vanni, A., Spinicci, M., Mencarini, J., Caporale, R., Peruzzi, B., Antonelli, A., Trotta, M., Zammarchi, L., Ciani, L., Gori, L., Lazzeri, C., Matucci, A., Vultaggio, A., Rossi, O., Almerigogna, F., Parronchi, P., Fontanari, P., Lavorini, F., Peris, A., Rossolini, G., Baroloni, A., Romaganani, S., Liotta, F., Annunziato, F., Cosmi, L.. Impaired immune cell cytotoxicity in severe COVID19 is IL-6 dependent. J Clin Invest. (2020). doi: 10.1172/JCI138554. 
14. Mehta, P., McAuley, D., Brown, M., Sanchez, E., Tattersall, R., Manson, J. COVID-19: consider cytokine storm syndromes and immunosuppression. The Lancet. (2020). doi: 10.1016/ S01406736(20)30628-0.

15. Beigel, J., Tomashek, K., Dodd, L., Mehta, A., Zingman, B., Kalil, A., Hohmann, E., Chu, H., Luetkemeyer, A., Kline, S., Castilla, D., Finberg, R., Dierberg, K., Tapson, V., Hsieh, L., Patterson, T., Paredes, R., Sweeney, D., Short, W., Touloumi, G., Lye, D., Ohmagari, N., Oh, M., Ruiz-Palacios, G., Benfield, T., Fatkenheuer, G., Kortepeter, M., Atmar, R., Creech, B., Lundgren, J., Babiker, A., Pett, S., Neaton, J., Burgess, T., Bonnett, T., Green, M., Makowski, M., Osinusi, A., Nayak, S., Lane, H. Remdesivir for the Treatment of Covid-19 - Preliminary Report. The New England Journal of Medicine. (May 22, 2020). doi: 10.1056/NEJMoa2007764

16. Hernandez, A., Roman, Y., Pasupuleti, V., Barboza, J., White, C. Hydroxychloroquine or Chloroquine for Treatment or Prophylaxis of COVID-19: A Living Systematic Review. Annals of Internal Medicine. (May 27, 2020). doi: 10.7326/M20-2496

17. Russell, C., Millar, J., \& Baillie J. Clinical evidence does not support corticosteroid treatment for 2019nCoV lung injury. The Lancet. (2020). 395(10223):473-475. doi: 10.1016/s0140-6736(20)30317-2.

18. Alhazzani, W., Moller, M., Arabi, Y., Loeb, M., Gong, M., Fan, E., Oczkowski, S., Levy, M., Derde, L., Dzierba, A., Du, B., Aboodi, M., Wunsch, H., Cecconi, M., Koh, Y., Chertow, D., Maitland, K., Alshamsi, F., Belley-Cote, E., Greco, M., Laundy, M., Morgan, J., Kesecioglu, J., McGeer, A., Mermel, L., Mammen, M., Alexander, P., Arrington, A., Centofanti, J., Citerio, G., Baw, B., Memish, Z., Hammond, N., Hayden, F., Evans, L., Rhodes, A. Surviving Sepsis Campaign: guidelines on the management of critically ill adults with Coronavirus Disease 2019 (COVID-19). Intensive Care Med. 2020; 46:854-887. doi: 10.1007/s00134020-06022-5

19. Horby, P., Lim, W., Emberson, J., Mafham, M., Bell, J., Linsell, L., Staplin, N., Brightling, C., Ustianowski, A., Elmahi, E., Prudon, B., Green, C., Felton, T., Chadwick, D., Rege, K., Fegan, C., Chappell, L., Faust, S., Jaki, T., Jeffrey, K., Montgomery, A., Rowan, K., Juszczak, E., Baillie, J., Haynes, R., Landray, M. Effect of Dexamethasone in Hospitalized Patients with COVID-19: Preliminary Report. medRxiv. (June 22, 2020). doi: 10.1101/2020.06.22.20137273

20. "Clinical management of COVID-19." World Health Organization. (May 27, 2020). Retrieved from https://www.who.int/publications-detail/clinical-management-of-severe-acute-respiratory-infectionwhen-novel-coronavirus-(ncov)-infection-is-suspected

21. Coomes E. \& Haghbayan H. Interleukin-6 in COVID-19: A Systematic Review and Meta-Analysis. MedRxiv (2020). doi: 10.1101/2020.03.30.20048058

22. Velazquez-Salinas, L., Verdugo-Rodriguez, A., Rodriguez, L, Borca, M. The Role of Interleukin 6 During Viral Infections. Front Microbiol. (2019) doi: 10.3389/fmicb.2019.01057."

23. Ip, A., Berry, D., Hansen, E., Goy, A., Pecora, A., Sinclaire, B., Bednarz, U., Marafelias, M., Berry, S., Berry, N., Mathura, S., Sawczuk I., Biran, N., Go, R., Serber, S., Piwoz, J., Balani, B., Cicogna, C., Sebti, R., Zuckerman, J., Rose, K., Tank, L., Jacobs, L., Korcak, J., Timmapuri, S., Underwood, J., Sugalski, G., Barsky, C., Varga, D., Asif, A., Landolfi, J., Goldberg, S. Hydroxychloroquine and Tocilizumab Therapy in COVID-19 Patients - An Observational Study. medRxiv. (May 25, 2020). doi: 10.1101/2020.05.21.20109207

Peer) reviewing PDF | (2020:09:52525:1:1:NEW 1 Oct 2020) 
24. "Roche provides an update on the phase III COVACTA trial of Actemra/RoActemra in hospitalised patients with severe COVID-19 associated pneumonia." Roche. (July 29, 2020). Retrieved from https://www.roche.com/investors/updates/inv-update-2020-07-29.htm

25. "Sanofi and Regeneron's Kevzara fails in Phase III Covid-19 trial." Clinical Trials Arena. (July 3, 2020). Retrieved from https://www.clinicaltrialsarena.com/news/kevzara-us-covid19-trial-data/

26. Cortegiani, A., Ippolito, M., Greco, M., Granone, V., Protti, A., Gregoretti, C., Giarratano, A., Einav, S., Cecconi, M. Rational and evidence on the use of tocilizumab in COVID-19: a systematic review. Pulmonology. (July 20, 2020). doi: 10.1016/j.pulmoe.2020.07.003

27. Aziz, M., Haghbin, H., Sitta, E., Nawras, Y., Fatima, R., Sharma, S., Lee-Smith, W., Duggan, J., Kammeyer, J., Hanrahan, J., Assaly, R. Efficacy of Tocilizumab in COVID-19: A Systematic review and Meta-Analysis. Journal of Medical Virology. (September 12, 2020). doi: 10.1002/jmv.26509

28. Moher, D., Liberati, A., Tetzlaff, J., Altman, D. The PRISMA Group (2009). Preferred Reporting Items for Systematic Reviews and Meta-Analyses: The PRISMA Statement. PLoS Med. (2009). 6(6). doi: 10.1371/journal.pmed1000097

29. Klopfenstein, T., Zayet, S., Lohse, A., Balblanc, J-C., Badie, J., Royer, P-Y., Toko, L., Mezher, C., Kadiane-Oussou, N., Bossert, M., Bozgan, A-M., Charpentier, A., Roux, M-F., Conteras, R., Mazurier, I., Dussert, P., Gedrin, V., Conrozier, T. Tocilizumab therapy reduced intensive care unit admissions and/or mortality in COVID-19 patients. Med Mal Infect. (May 6, 2020). doi: 10.1016/j.medmal.2020.05.001

30. Campochiaro, C., Della-Torre, E., Cavalli, G., De Luca, G., Ripa, M., Boffini, N., Tomelleri, A., Baldissera, E., Rovere-Querini, P., Ruggeri, A., Monti, G., De Cobelli, F., Zangrillo, A., Tresoldi, M., Castagna, A., Dagna, L., Andelillo, P., Assanelli, A., Baldissera, E., Boffini, N., Calvisi, S., Canetti, D., Cariddi, A., Castagna, A., Cavalli, G., Ciceri, F., Dagna, L., De Covelli, F., Della Torre, E., Farina, N., Fazio, M., Landoni, G., Mancuso, G., Marinosci, A., Monti, G., Oltolini, C., Ripa, M., Sartorelli, S., Scarpellini, S., Spessot, M., Tomelleri, A., Tresoldi, M., Zangrillo, A. Efficacy and safety of tocilizumab in severe COVID19 patients: a single-centre retrospective cohort study. European Journal of Internal Medicine. (May 22, 2020). doi: 10.1016/j.ejim.2020.05.021

31. Capra, R., Rossi, N., Mattioli, F., Romanelli, G., Scarpazza, C., Sormani, M., Cossi, S. Impact of low dose tocilizumab on mortality rate in patients with COVID-19 related pneumonia. European Journal of Internal Medicine. (May 6, 2020). doi: 10.1016/j.ejim.2020.05.009

32. Colaneri, M., Bogliolo, L., Valsecchi, P., Sacchi, P., Zuccaro, V., Brandolino, F., Montecucco, C., Mojoli, F., Giusti, E., Bruno, R. Tocilizumab for Treatment of Severe COVID-19 Patients: Preliminary Results from SMAtteao COvid19 Registry (SMACORE). Microorganisms. (May 9, 2020).

10.3390/microorganisms8050695

33. Rojas-Marte, G., Khalid M., Mukhtar O., Hashmi, A., Waheed, M., Ehrlich, S., Aslam, A., Siddiqui, S>, Agarwal, C., Malyshev, Y., Henriquiez-Felipe, C., Sharma, D., Sharma, S., Chukwuka, N., Rodriguez, D., Alliu, S., Shani, J. Outcomes in Patients with Severe COVID-19 Disease Treated with Tocilizumab - A CaseControlled Study. QJM. (June 23, 2020). doi: 10.1093/qjmed/hcaa206

34. Wadud, N., Ahmed, N., Shergil, M., Khan, M., Krishna, M., Gilani, A., Zarif, S., Galaydick, J., Linga, K., Koor, S., Galea, J., Stuczynski, L., Osundele, M. Improved survival outcome in SARs-CoV-2 (COVID-19)

Peer) reviewing PDF | (2020:09:52525:1:1:NEW 1 Oct 2020) 
477

478

479

480

481

482

483

484

485

486

487

488

489

490

491

492

493

494

495

496

497

498

499

500

501

502

503

504

505

506

507

508

509

510

511

512

513

514

515

Acute Respiratory Distress Syndrome patients with Tocilizumab administration. medRxiv. (May 16, 2020). doi: 10.1101/2020.05.13.20100081

35. Roumier, M., Paule, R., Groh, M., Vallee, A., Ackermann. Interleukin-6 blockade for severe COVID-19. medRxiv. (March 22, 2020). doi: 10.1101/2020.04.20.20061861

36. Guaraldi, G., Meschiari, M., Cozzi-Lepri, A., Milic., J., Tonelli, R., Menozzi, M., Franceschini, E., Cuomo, G., Orlando, G., Borghi, V., Santoro, A., Di Gaetano, M., Puzzolante, C., Carli, F., Bedini, A., Corradi, L., Fantini, R., Castaniere, I., Tabbi, L., Giardis, M., Tedeschi, S., Giannella, M., Bartolletti, M., Pascale, R., Dolci, G., Brugioni, L., Pietrangelo, A., Cossarizza, A., Pea, F., Clini, E., Salvarani, C., Massari, M., Viale, P., Mussini, C. Tocilizumab in patients with severe COVID-19: a retrospective cohort study. The Lancet. (June 24, 2020). 10.1016/S2665-9913(20)30173-9

37. Patel, K., Gooley, T., Bailey, N., Bailey, M., Hegerova, L., Batchelder, A., HOldread, H., Dunleavy, V., Downey, T., Frisvold, J., Megrath, S., Pagarigan, K., Szeto, J., Rueda, J., Islam, A., Maree, C., Nyatsatsang, S., Bork, S., Lipke, A., O’Mahony, S., Wagner, T., Pulido, J., Mignone, J., Youssef, S., Hartman, M., Goldman, J., Pagel, J. Use of the IL-6R Antagonist Tocilizumab in Hospitalized COVID-19 Patients. Journal of Internal Medicine, (August 4, 2020). doi: 10.1111/joim.13163

38. Eimer, J., Vesterbacka, J., Svensson, A., Stojaovic, B., Wagrell, C., Sonnerborg, A., Nowak, P. Tocilizumab shortens time on mechanical ventilation and length of hospital stay in patients with severe COVID-19: a retrospective cohort study. Journal of Internal Medicine. (August 4, 2020). doi: 10.1111/joim.13162

39. Canziani, L., Trovati, S., Brunetta, E., Testa, A., De Santis, M., Bombardieri, E., Guidelli, G., Albano, G., Folci, M., Squadroni, M., Beretta, G., Ciccarelli, M., Castoldi, M., Lleo, A., Aghemo, A., Vernile, L., Malesci, A., Omodei, P., Angelini, C., Badalamenti, S., Cecconi, M., Cremonesi, A., Selmi, C. Interleukin- 6 receptor blocking with intravenous tocilizumab in COVID-19 severe acute respiratory distress syndrome: $\mathrm{A}$ retrospective case-control survival analysis of 128 patients. Journal of Autoimmunity. (July 28, 2020). doi: 10.1016/j.jaut.2020.102511

40. Gokhale, Y., Mehta, R., Karnik, N., Kulkarni, U., Gokhale, S. Tocilizumab improves survival in patients with persistent hypoxia in severe COVID-19 pneumonia. EClinicalMedicine. (July 22, 2020). doi: 10.1016/j.eclinm.2020.100467

41. Rossotti, R., Travi, G., Ughi, N., Corradin, M., Baiguera, C., Fumagalli, R., Bottiroli, M., Mondino, M., Merli, M., Bellone, A., Baisle, A., Ruggeri, R., Colombo, F., Moreno, M., Pastori, S., Perno, C., Tarsia, P., Epis, O., Puoti, M. Safety and efficacy of anti-il6-receptor tocilizumab use in severe and critical patients affected by coronavirus disease 2019: A comparative analysis. Journal of Infection. (July 12, 2020). doi: 10.1016/j.jinf.2020.07.008

42. Somers, E., Eschenauer, G., Troost, J., Golob, J., Gandhi, T., Wang, L., Zhou, N., Petty, L., Baang, J., Dillman, N., Frame, D., Gregg, K., Kaul, D., Nagel, J., Patel, T., Zhou, S., Lauring, A., Hanauer, D., Martin, E., Sharma, P., Fung, C., Pogue, J. Tocilizumab for treatment of mechanically ventilated patients with COVID-19. Clinical Infectious Diseases. (July 11, 2020). doi: 10.1093/cid/ciaa954

43. Potere, N., Di Nisio, M., Cibelli, D., Scurti, R., Antonella, F., Porreca, E., Abbate, A., Parruti, G. Interleukin-6 receptor blockade with subcutaneous tocilizumab in severe COVID-19 pneumonia and 
516 hyperinflammation: a case-control study. Ann Rheum Dis. (July 11, 2020). doi: 10.1136/annrheumdis-

$517 \quad 2020-218243$

518 44. Richardson, S., Hirsch, J., Narasimhan, M., Crawford, J., McGinn, T., Davidson, K. Presenting

519 Characteristics, Comorbidities, and Outcomes Among 5700 Patients Hospitalized With COVID-19 in the

520 New York City Area. JAMA. (April 22, 2020); 323(20): 2052-2059. doi:10.1001/jama.2020.6775

521 45. Luo, P., Liu, Y., Qiu, L., Liu, X., Liu, D., Li, J. Tocilizumab treatment in COVID-19: A single center

522 experience. Journal of Medical Virology. (March 26, 2020). 10.1002/jmv.25801

523 46. Toniati, P., Piva, S., Cattalini, M., Garrafa, E., Regola, F., Castelli, F., Franceschini, F., Airo, P., Bazzani,

524 C., Beindorf, E., Berlendis, M., Bezzi, M., Bossini, N., Castellano, M., Cattaneo, S., Cavazzna, I., Contessi,

525 G., Crippa, M., Delbarba, A., De Peri, E., Faletti, A., Filippini, M., Filippini, M., Frassi, M., Gaggiotti, M.,

526 Gorla, R., Lanspa, M., Lorenzotti, S., Marino, R., Maroldi, R., Metra, M., Matteelli, A., Modina, D., Moioli,

527 G., Montani, M., Muiesan, M., Odolini, S., Peli, E., Pesenti, S., Pezzoli, M., Pirola, I., Pozzi, A., Proto, A.,

528 Rasulo, F., Renisi, G., Ricci, C., Rizzoni, D., Romanelli, G., Rossi, M., Salvetti, M., Scolari, F., Signorini, L.,

529 Taglietti, M., Tomasoni, G., Tomasoni, L.., Turla, F., Valsecchi, A., Zani, D., Zuccala, F., Zunica, F., Foca, E.,

530 Andreoli, L., Latronico, N. Tocilizumab for the treatment of severe COVID-19 pneumonia with

531 hyperinflammatory syndrome and acute respiratory failure: A single center study of 100 patients in

532 Brescia, Italy. Autoimmunity Reviews. (May 3, 2020). 19(7):102568. doi: 10.1016/j.autrev.2020.102568

533 47. Xu, X., Han, M., Li, T. Effective treatment of severe COVID-19 patients with tocilizumab. PNAS. (May

53419 2020). doi: 10.1073/pnas.2005615117

535 48. Price, C., Altice, F., Shyr, Y., Koff, A., Pischel, L., Goshua, G., Azar, M., Mcmanus, D., Chen, S., Gleeson,

536 S., Britto, C., Azy, V., Kaman, K., Gaston, D., Davis, M., Burrello, T., Harris, Z., Villanueva, M., Aoun-

537 Barakat, L., Kang, I., Seropian, S., Chupp, G., Bucala, R., Kaminski, N., Lee, A., LoRusso, P., Topal, J.,

538 CelaCruz, C., Malinis, M.Tocilizumab treatment for Cytokine Release Syndrome in hospitalized COVID-19

539 patients: survival and clinical outcomes. Chest. (June 20, 2020). doi: 10.1016/j.chest.2020.06.006

540 49. Sciascia, S., Apra, F., Baffa, A., Baldovino, S., Boaro, D., Boero, R., Bonora, S., Calcagno, A., Cecchi, I.,

541 Cinnirella, G., Converso, M., Cozzi, M., Crosasso, P., De laco, F., Di Perri G., Eandi, M., Fenoglio, R., Giusti,

542 M., Imperiale, D., Imperiale, G., Livigni, S., Manno, E., Massara, C., Milone, V., Natale, G., Navarra, M.,

543 Oddone, V., Osella, S., Piccioni, P., Radin, M., Roccatello, D., Rossi, D. Pilot prospective open, single-arm

544 multicentre study on off-label use of tocilizumab in patients with severe COVID-19. Clinical and

545 Experimental Rheumatology. (May 1, 2020); 38: 529-532.

546 50. Alattar, R., Ibrahim, T., Shaar, S., Abdalla, S>, Shukri, K., Daghfal, J., Khatib, M., Aboukamar, M.,

547 Abukhattab, M., Alsoub, H., Almaslamani, M., Omrani, A. Tocilizumab for the treatment of severe

548 coronavirus disease 2019. Journal of Medical Virology. (May 5, 2020). doi: 10.1002/jmv.25964

549 51. Issa, N., Dumery, M., Guisset, O., Mourissoux, G., Bonnet, F., Camou, F. Feasibility of Tocilizumab in

550 ICU patients with COVID-19. Journal of Medical Virology. (June 3, 2020). doi: 10.1002/jmv.26110

551 52. Quartuccio, L., Sonaglia, A., McGonagle, D., Fabris, M., Peghin, M., Pecori, D., De Monte, A., Bove, T.,

552 Curcio, F., Bassi, F., De Vita, S., Tascini, C. Profiling COVID-19 Pneumonia progressing into the cytokine

553 storm syndrome: results from a single Italian Centre study on tocilizumab versus standard of care.

554 Journal of Clinical Virology. (May 15, 2020). doi: 10.1016/j.jcv.2020.104444

Peer] reviewing PDF | (2020:09:52525:1:1:NEW 1 Oct 2020) 
53. Campins, L., Boixeda, R., Perez-Cordon, L., Aranega, R., Lopera, C., Force, L. Early tocilizumab treatment could improve survival among COVID-19 patients. Clinical Experimental Rheumatology. (May 28, 2020). PMID: 32456769

54. Morena, V., Milazzo, L., Oreni, L., Bestetti, G., Fossali, T., Bassoli, C., Torre, A., Cossu, M., Minari, C., Ballone, E., Perotti, A., Mileto, D., Niero, F., Merli, S., Foschi, A., Vimercati, S., Rizzardini, G., Sollima, S., Bradanini, L., Galimberti, L., Colombo, R., Micheli, V., Negri, C., Ridolfo, a., Meroni, L., Galli, M., Antinori, S., Corbellino. Off-label use of tocilizumab for the treatment of SARS-CoV-2 pneumonia in Milan, Italy. European Journal of Internal Medicine. (May 21, 2020). doi: 10.1016/j.ejim.2020.05.011

55. Borku Uysal, B., Ikitimur, H., Yavuzer, S., Ulkitimur, B., Uysal, H., Islamoglu, M., Ozcan, E., Aktepe, E., Yavuzer, H., Cengiz. Tocilizumab challenge: A series of cytokine storm therapy experience in hospitalized Covid-19 pneumonia patients. Journal of Medical Virology. (June 3, 2020). 10.1002/jmv.26111

56. Strohbehn, G., Heiss, B., Rouhani, S., Trujillo, J., Yu, J., Kacew, A., Higgs, E., Bloodworth, J., Cabanov, A., Wright, R., Koziol, A., Weiss, A., Danahey, K., Karrison, T., Edens, C., Ventura, I., Pettit, N., Patel, B., Pisano, J., Strek, M., Gajewski, T., Ratain, M., Reid, P. COVIDOSE: Low-dose tocilizumab in the treatment of Covid-19. medRxiv. (August 4, 2020). doi: 10.1101/2020.07.20.20157503

57. Patel, A., Shah, K., Dharsandiya, M. Patel, K., Patel, T., Patel, M., Reljic, T., Kumar, A. Safety and efficacy of tocilizumab in the treatment of severe acute respiratory syndrome coronavirus-2 pneumonia: A retrospective cohort study. Medical Microbiology. (July 29, 2020). doi: 10.4103/ijmm.IJMM_20_298

58. Tomasiewicz, K., Piekarska, A., Stempkowska-Rejek, J., Serafinska, S., Gawkowska, A., Parczewski, M., Niscigorska-Olsen, J., Lapinski, T., Zarebska-Michaluk, D., Kowalska, J., Horban, A., Flisiak, R. Tocilizumab for patients with severe COVID-19: a retrospective, multi-center study. Expert Review of Anti-infective Therapy. (July 23, 2020). doi: 10.1080/14787210.2020.1800453

59. Moreno-Pérez, O., Andres, M., Leon-Ramirez, JM., Sanchez-Paya, J., Rodriguez, J., Sanchez, R., Garcia-Sevila, R., Boix, V., Gil, J., Merino, E. Experience with tocilizumab in severe COVID-19 pneumonia after 80 days of follow-up: A retrospective cohort study. Journal of Autoimmunity. (July 22, 2020). doi: 10.1016/j.jaut.2020.102523

60. Fernández-Ruiz, M., López-Medrano, F., Asín, M., de la Calle, M., Bueno, H., Caro-Teller, J., Catalan, M., de la Calle, C., Garcia, R., Gomez, C., Laguna-Goya, R., Lizasoain, M., Martinez-Lopez, J., Origuen, J., Pablos, J., Ripoll, M., Juan, R., Trujillo, H., Lumbreras, C., Aguado, J. Tocilizumab for the treatment of adult patients with severe COVID-19 pneumonia: A single-center cohort study. Journal of Medical Virology. (July 17, 2020). doi: 10.1002/jmv.26308

61. Knorr J., Colomy, V., Mauriello, C., Ha, S. Tocilizumab in patients with severe COVID-19: A singlecenter observational analysis. Journal of Medical Virology. (July 7, 2020). doi: 10.1002/jmv.26191

62. Jordan, S., Zakowski, P., Tran, H., Smith, E., Gaultier, C., Marks, G., Zabner, R., Lowenstein, H., Oft, J., Bluen, B., Le, C., Shane, R., Ammerman, N., Vo, A., Chen, P., Kumar, S., Toyoda, M., Ge, S., Huang, E. Compassionate Use of Tocilizumab for Treatment of SARS-CoV-2. Clinical of Infectious Diseases. (June 24, 2020). doi: 10.1093/cid/ciaa812 
Figure 1

\section{PRISMA Flow Diagram for Systematic Review Article Search}
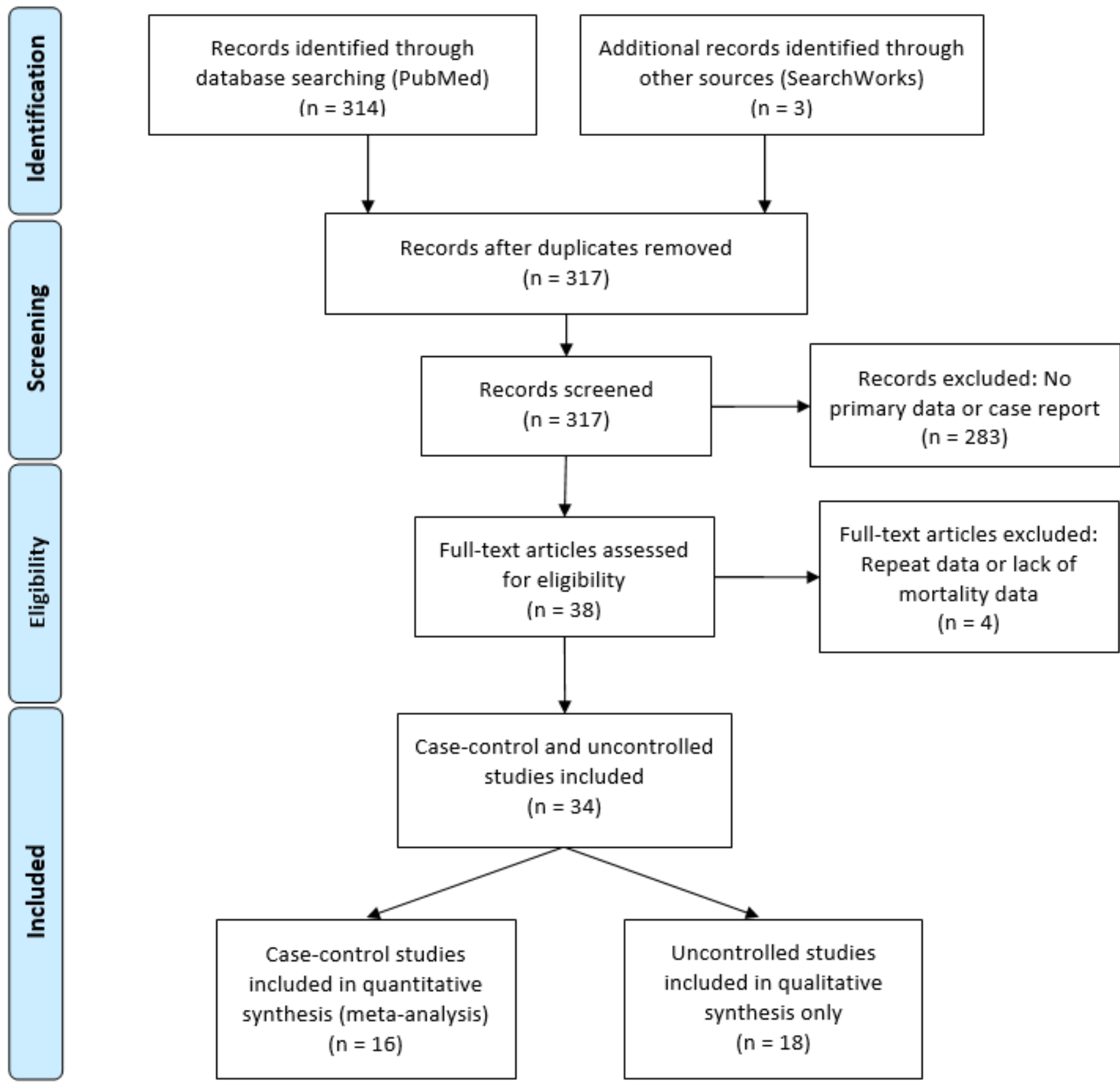


\section{Figure 2}

\section{Responses to IL-6 Release and Their Physiological Effects}

Red indicates negative consequences of IL-6 increase while green designates positive ones in COVID-19.

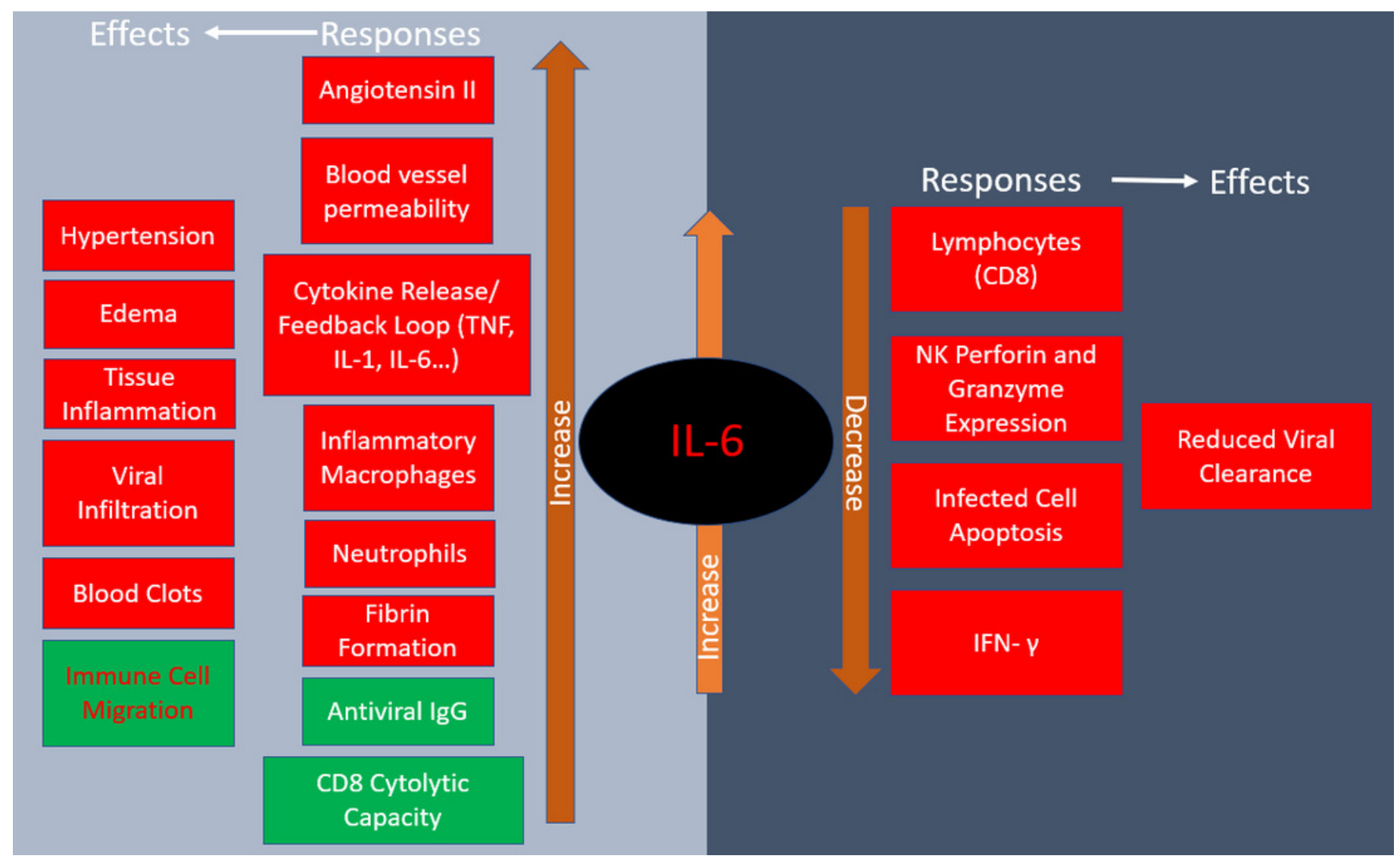




\section{Figure 3}

IL-6 Pathway and TCZ Mechanism of Action

Simplified schematic of IL-6 pathway and TCZ mechanism of action. After SARS-CoV-2

infection, immune cells - predominately macrophages - release cytokines including IL-6. IL-6 can either attach to its respective cell receptor (IL-6R) or soluble receptor (SIL-6R) which activates both the NF-KB and JAK/STAT pathways that can induce a cytokine storm. ${ }^{21} \mathrm{TCZ}$ antibodies can bind to the IL-6R and SIL-6R to prevent signal transduction and reduce the chance of cytokine storm. ${ }^{11}$ 


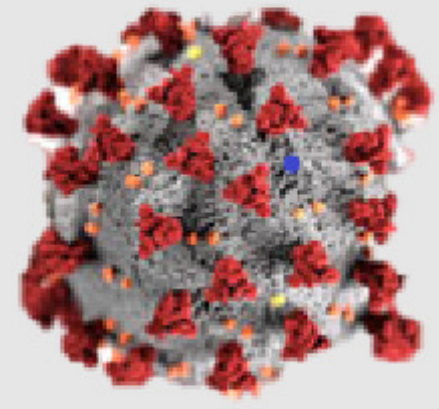

SARS-CoV-

2 Infection
Immune Cell Activation

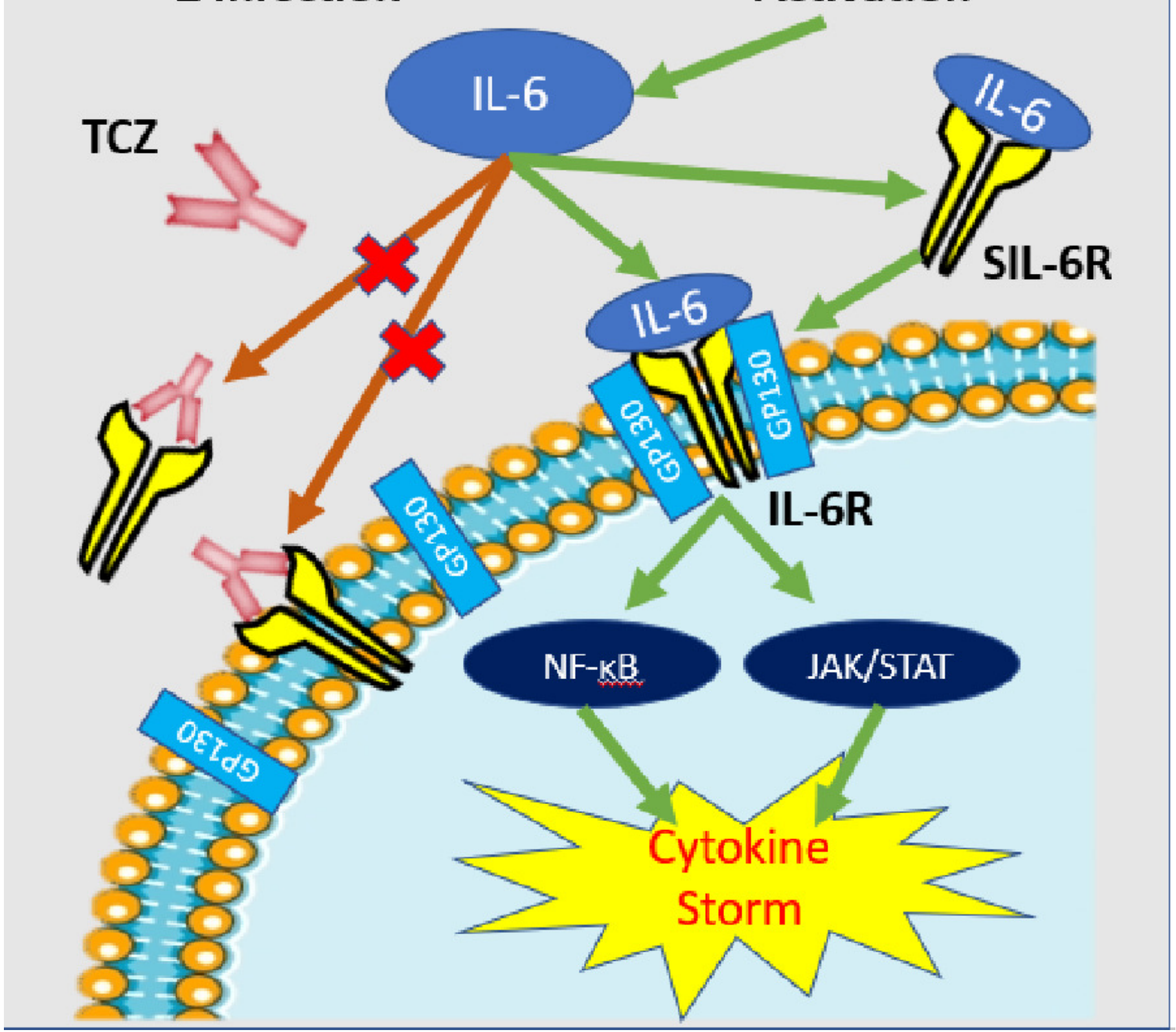




\section{Table 1 (on next page)}

Quantitative Synthesis of Individual Case-Control Study Mortality Data 
1 Table 1: Quantitative Synthesis of Individual Case-Control Study Mortality Data

\begin{tabular}{|c|c|c|c|c|c|c|}
\hline Study & TCZ Mortality & Controls & Odds ratio & $95 \% \mathrm{Cl}$ & $\begin{array}{c}\text { Weight \% } \\
\text { (Random } \\
\text { Effects) }\end{array}$ & $\begin{array}{c}p \\
\text { Value }\end{array}$ \\
\hline Klopfenstein et al. ${ }^{29}$ & $4 / 20(20 \%)$ & $12 / 25(48 \%)$ & 0.271 & $\begin{array}{c}0.0704- \\
1.042\end{array}$ & 3.54 & 0.0575 \\
\hline $\begin{array}{c}\text { Campochiaro et } \\
\text { al. }^{30}\end{array}$ & $5 / 32(15.6 \%)$ & 11/33 (33.3\%) & 0.37 & $0.112-1.227$ & 4.23 & 0.104 \\
\hline Capra et al. ${ }^{31}$ & $2 / 62(3.2 \%)$ & $11 / 23(47.8 \%)$ & 0.0364 & $\begin{array}{c}0.00713- \\
0.185\end{array}$ & 2.61 & 0.0001 \\
\hline Colaneri et al..$^{32}$ & $5 / 21(23.8 \%)$ & $6 / 21(28.6 \%)$ & 0.781 & $0.197-3.106$ & 3.41 & 0.726 \\
\hline Rojas-Marte et al. ${ }^{33}$ & $50 / 96(52.1 \%)$ & $60 / 97$ (61.9\%) & 0.67 & $0.378-1.189$ & 9.7 & 0.171 \\
\hline Wadud et al. ${ }^{34}$ & $17 / 44(38.6 \%)$ & $26 / 50(52 \%)$ & 0.581 & $0.255-1.323$ & 6.9 & 0.196 \\
\hline Ip et al. ${ }^{23}$ & $\begin{array}{l}62 / 134 \\
(46.3 \%)\end{array}$ & $\begin{array}{l}231 / 413 \\
(55.9 \%)\end{array}$ & 0.678 & 0.459-1.003 & 12.2 & 0.0519 \\
\hline Roumier et al. ${ }^{35}$ & $3 / 30(10 \%)$ & $9 / 30(30 \%)$ & 0.259 & $\begin{array}{c}0.0623- \\
1.079\end{array}$ & 3.24 & 0.0635 \\
\hline Guaraldi et al. ${ }^{36}$ & $13 / 179(7.3 \%)$ & $73 / 365(20 \%)$ & 0.309 & $\begin{array}{c}0.2166- \\
0.574\end{array}$ & 9.11 & 0.0002 \\
\hline Patel et al. ${ }^{37}$ & $11 / 42(26.2 \%)$ & $11 / 41(28.6 \%)$ & 0.968 & $0.355-2.565$ & 5.62 & 0.947 \\
\hline Eimer et al. ${ }^{38}$ & $4 / 22(18.2 \%)$ & $7 / 22(31.8 \%)$ & 0.476 & $0.116-1.94$ & 3.31 & 0.301 \\
\hline Canziani et al. ${ }^{39}$ & $17 / 64(26.6 \%)$ & 24/64 (37.5\%) & 0.603 & $0.285-1.277$ & 7.61 & 0.187 \\
\hline Gokhale et al..$^{40}$ & $33 / 70(47.1 \%)$ & $61 / 91(67 \%)$ & 0.345 & $0.185-0.644$ & 8.85 & 0.0008 \\
\hline Rossotti et al. ${ }^{41}$ & $20 / 74(26.4 \%)$ & $86 / 146$ (58.9\%) & 0.517 & $0.301-0.887$ & 9.23 & 0.0166 \\
\hline Somers et al. ${ }^{42}$ & $14 / 78(17.9 \%)$ & $22 / 76(35.5 \%)$ & 0.379 & $0.189-0.836$ & 7.67 & 0.0151 \\
\hline Potere et al. ${ }^{43}$ & $2 / 40(5 \%)$ & $12 / 40(30 \%)$ & 0.123 & $\begin{array}{c}0.0254- \\
0.593\end{array}$ & 2.76 & 0.009 \\
\hline $\begin{array}{c}\text { Total (random } \\
\text { effects) }\end{array}$ & $\begin{array}{c}262 / 1008 \\
(26.0 \%)\end{array}$ & $\begin{array}{c}667 / 1537 \\
(43.4 \%)\end{array}$ & 0.453 & $0.376-0.547$ & 100 & $<0.001$ \\
\hline
\end{tabular}

2 
Figure 4

Odds Ratio of Mortality from Severe COVID-19 Between TCZ and Standard of Care

Forrest plot depicting odds ratio for death from severe COVID-19 with TCZ versus the SOC.

Center point on each line is the odds ratio for the study with the size of the circle correlating to the percent contribution to the total random effects calculation. Horizontal length corresponds to the $95 \% \mathrm{Cl}$. The Total (Random Effects) synthesizes data from the 16 individual case-control studies.

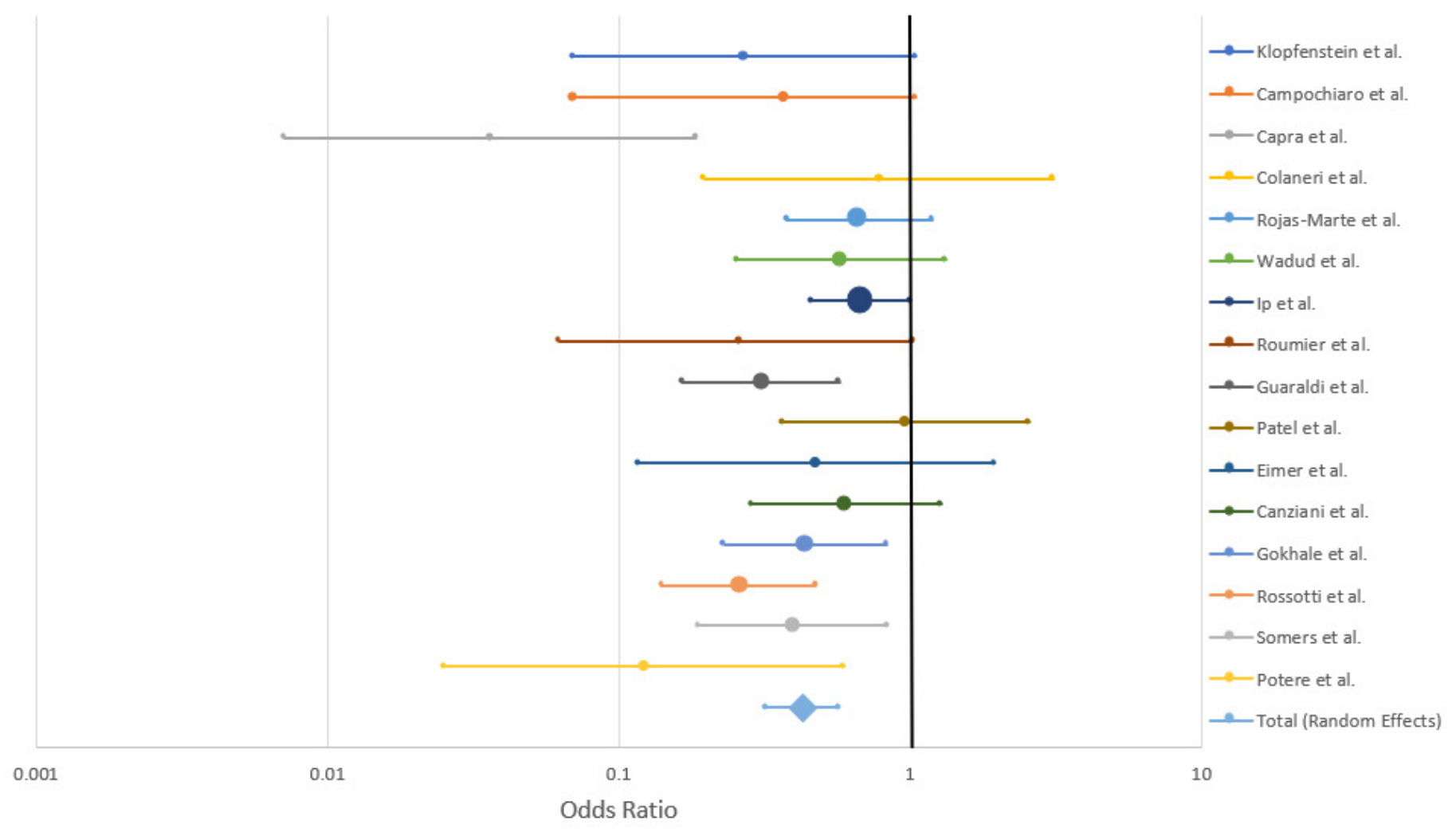


Figure 5

Funnel Plot of Controlled Trials to Detect Potential Publication Bias

Funnel plot relating the odds ratio to the standard of the effect estimate for each study. Vertical blue line depicts the overall random effects odds ratio.

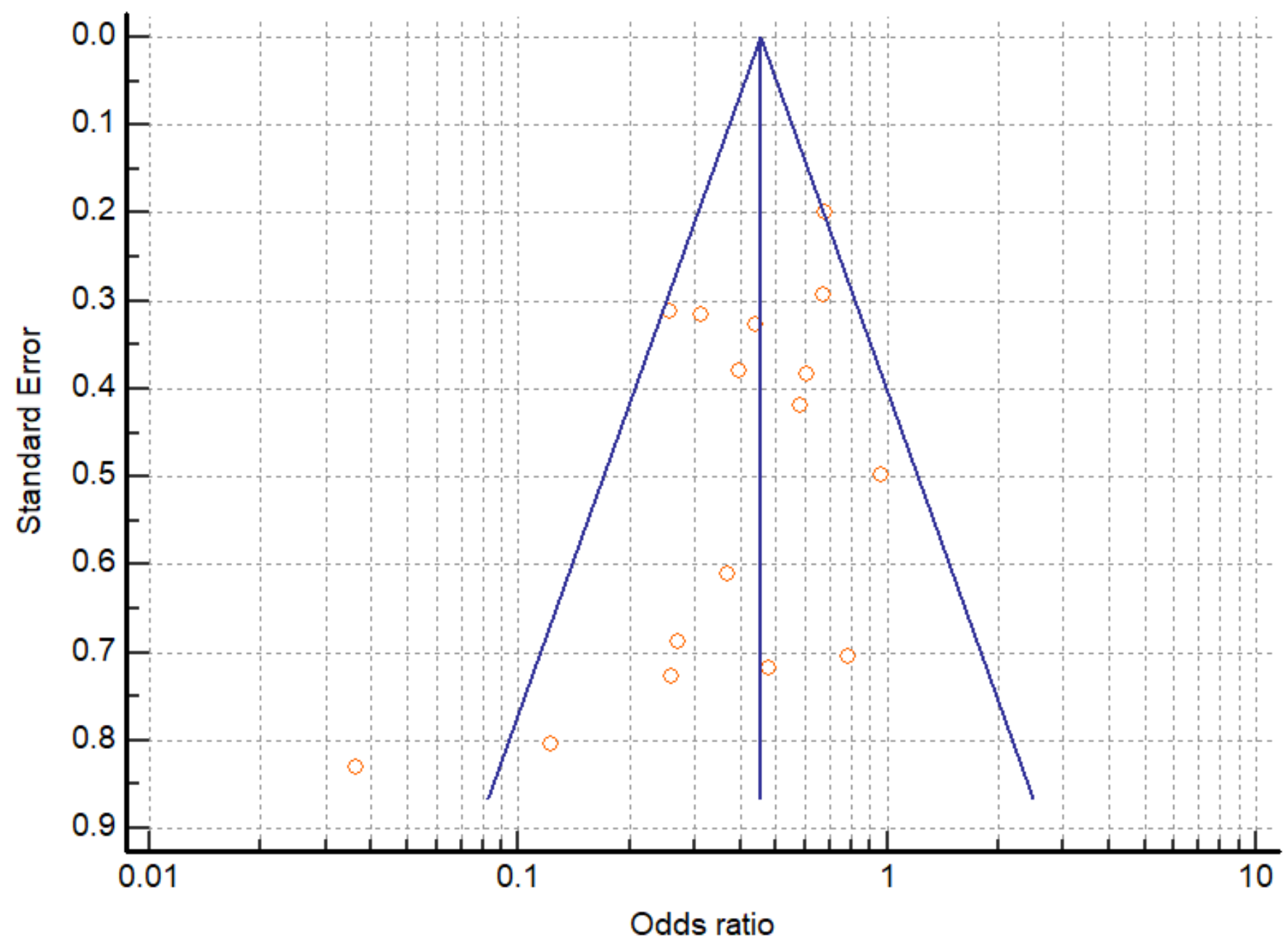




\section{Table 2 (on next page)}

Mortality Rate Comparison Between Controlled and Uncontrolled Trials

Comparison of mortality rate between controlled $(n=14)$ and uncontrolled $(n=18)$ studies. Mortality and total patient values are simple tallies from each study. 
1 Table 2: Mortality Rate Comparison Between Controlled and Uncontrolled Trials

\begin{tabular}{|c|c|c|c|c|} 
& Mortalities & Total & Mortality Rate & SD \\
\hline Controlled & 150 & 778 & $19.3 \%$ & $11.9 \%$ \\
\hline Uncontrolled & 141 & 886 & $16.0 \%$ & $9.87 \%$ \\
\hline Difference & $3.3 \%$ & & & \\
\hline 95\% Cl & $-10.91-4.31$ & & & \\
\hline $\begin{array}{c}\text { Significance } \\
\text { Value }\end{array}$ & $\mathrm{p}=0.384$ & & & \\
\hline
\end{tabular}

2 Table 2: Comparison of mortality rate between controlled $(n=14)$ and uncontrolled $(n=18)$ studies.

3 Mortalities and total patient values are simple tallies from each study. 